\title{
Short term comparative study of topical $2 \%$ carteolol with and without benzalkonium chloride in healthy volunteers
}

\author{
Christophe Baudouin, Christine de Lunardo
}

\begin{abstract}
Aim-A crossover, randomised double blind study was undertaken in 30 healthy volunteers, in order to compare the tolerance of $2 \%$ carteolol with and without preservative in short term use.

Methods-Complete ophthalmic examinations were performed before and 30,60 , and 180 minutes after instillation of one drop of the solution, and after 3 days of preservative treatment. After a 5 day washout, the same examinations were done with the second drug.

Results-Results showed good general tolerance for both formulations. No significant difference in subjective tolerance, corneal aesthesiometry, punctuate keratitis, Schirmer's test, intraocular pressure (IOP) decrease (about $25 \%$ in the two groups at 3 hours, $10 \%$ after 3 days of treatment), resting cardiac frequency, or blood pressure was observed. However, break up time was significantly reduced from baseline by preserved carteolol both at 3 hours $(10.40(5.9)$ seconds to $6.15(3.9)$ seconds, $p=0.001)$ and after 3 days $(7.72$ (5.5) seconds, $p=0.04)$. Preservative free carteolol did not significantly change the break up time (baseline 9.08 (5.7) seconds; 3 hours $=7.88$ (5.5) seconds, not significant; day $3=8.35$ (5.8), non-significant). Conclusions-These results confirm that carteolol is well tolerated, either with or without preservative. The preservative free group showed better stability of the tear film, without loss of effect on IOP. This difference, although mild in the healthy young subjects in the present study could be much more relevant in those patients treated long term, older patients, and/or those suffering from ocular surface disorders. In such instances, preservative free drugs could be of potential benefit to protect the lacrimal fluid integrity and corneoconjunctival surface. (Br F Ophthalmol 1998;82:39-42)
\end{abstract}

Long term use of antiglaucoma drugs has been associated with toxic as well as inflammatory changes of the ocular surface. Conjunctival biopsies taken at the time of glaucoma surgery have demonstrated a significant increase in immune cells and fibroblasts, possibly related to cumulative treatments with antiglaucoma drugs. ${ }^{12}$ Impression cytology specimens from long term treated patients have shown significant metaplastic changes ${ }^{3}$ and abnormal in- duction of inflammatory markers by epithelial cells in about $50 \%$ of eyes. ${ }^{4}$ Clinically these inflammatory and fibrotic anomalies may result in pseudopemphigoid, ${ }^{5}$ foreshortening of inferior fornix ${ }^{6}$ or significant reduction of success rate in glaucoma surgery. ${ }^{78}$

However, little is known concerning the accurate mechanisms of such toxic side effects in long term and/or multitreated glaucoma patients. Is the active drug responsible, as suggested by the significant toxicity demonstrated by adrenalin derivatives? Is it the preservative, benzalkonium chloride, which has shown toxicity on the ocular surface epithelia, ${ }^{9}$ or the eventual additive a consequence of their association? Very few studies have been done in humans and they have indicated an improvement at the ocular surface level following removal of preservative from the solution of the glaucoma medication. ${ }^{10-12}$ We thus undertook this prospective, crossover, double blind study in healthy volunteers, to compare, in short term use, the effects of $2 \%$ carteolol, a topical $\beta$ blocker with intrinsic sympathomimetic activity, widely used in the treatment of primary open angle glaucoma, ${ }^{13}$ with and without benzalkonium chloride.

\section{Patients and methods}

PATIENT SELECTION

This study was performed in healthy volunteers, in the Centre of Clinical Pharmacology of the University of Nice, France, after receiving the authorisation of the ethics committee (CCPPRB) of Marseilles, France. Selection criteria were: informed consent, age ranging from 18 to 40 years, normal ophthalmic examination, including best corrected visual acuity above 20/25, no subjective sensation such as itching, foreign body sensation or burning, normal slit lamp examination, break up time above or equal to 5 seconds, negative fluorescein staining, Schirmer's test superior or equal to $6 \mathrm{~mm}$ at 5 minutes, and IOP between 8 and $18 \mathrm{~mm} \mathrm{Hg}$. Subjects with history of ocular disease, cardiac or respiratory contraindication to $\beta$ blockers, topical or systemic medicines for less than 7 days before the experiment, except oral contraception, myopia more than 4 dioptres, history of ocular allergy, contact lens wearing, monophthalmos, or risk of pregnancy were not selected. Moreover, electrocardiogram, resting heart rate, and systemic pressure were recorded in the last 2 weeks before study. Subjects with any abnormality were not selected. At the end of the 
selection period, 30 healthy volunteers conformed to all these criteria and took part in the study.

\section{STUDY DESIGN}

Solutions of $2 \%$ carteolol were prepared with and without benzalkonium chloride $(0.005 \%$, as in the commercial solution: Cartéol, manufactured by Chauvin, Montpellier, France), in identical vials numbered in a randomised manner. One bottle was used for each instillation, so that six vials were used for each study period. Only one eye was tested and received the two formulations successively. Fifteen subjects received drugs into their right eye and the other 15 into the left eye. Drug and eye assignments were done with the help of a randomised computerised method. During the first study period, ophthalmic examinations were performed immediately before and 30, 60, and 180 minutes after the instillation of one drop of the tested solution. Subjects then instilled one drop twice a day for 2 days and one drop in the morning of the third day. New ophthalmic and general examinations were done 8 hours after the last instillation. After a 5 day washout period, the same experiment was done in the same eye, with the other solution.

\section{CLINICAL EXAMINATIONS}

Before the first instillation of carteolol solution, systemic pressure, heart rate, distant visual acuity, aesthesiometry, pupillary diameter, slit lamp scoring of conjunctival hyperaemia, oedema and epiphora, break up time, given by the mean of two successive measurements, fluorescein test, graded 0 to 4 according to the extent of staining, Schirmer's test at 5 minutes and applanation tonometry were recorded. In order to avoid a possible interaction with the preservative included in the anaesthetic used for applanation tonometry, we used a non-preserved anaesthetic $(0.4 \%$ oxybuprocaine, Cebesine, Chauvin). The carteolol solution was administered 30 minutes after applanation tonometry to avoid any interference of the anaesthetic in evaluation of tolerance. After the first instillation, immediate tolerance was therefore evaluated by the subject on a visual analogue scale from 0 (not irritating) to 100 (extremely irritating), and subjective sensations of itching, burning, foreign body sensation, and photophobia were recorded at 10 minutes by a scoring system of intensity ranging from 0 to 3 . If available, duration of sensation was recorded. All ophthalmic examinations were repeated at 30,60 , and 180 minutes, except pupil diameter and Schirmer's test. Systemic tension and heart pulse rate were recorded at 60 and 180 minutes. Following repeated administration, all examinations were performed 8 hours after the last instillation in each period. The second period was conducted under the same protocol with the other solution tested.

STATISTICAL ANALYSES

Comparability of subjects assigned to treatment sequence 1 (carteolol with benzalkonium followed by unpreserved carteolol) and se- quence 2 (unpreserved carteolol followed by the preserved solution) was assessed for each criterion using the Mann-Whitney nonparametric test. No carryover effect was detected and therefore data of both sequences were pooled. Analysis of variance was performed for each variable and time. In case of significant difference, Mann-Whitney U test or Wilcoxon test for paired variables were performed. $p$ Values under or equal to 0.05 were considered significant.

\section{Results}

The 30 volunteers in this study were 18 females and 12 males, 19 to 40 years old. Their mean age was 26.7 (SD 5.2) years. At the beginning of the study, before the first instillation, the two groups were fully comparable, as eyes receiving benzalkonium or not did not differ significantly in any ophthalmic or systemic criterion tested. Very few side effects were observed during the study. They were limited to three mild superficial punctate keratitis (two cases with benzalkonium and one case in the preservative free group), that were resolved in a few days without treatment, and did not call for the experiment to be stopped.

\section{SINGLE INSTILLATION}

Subjective tolerance at instillation quantified by a visual analogue scale from 0 to $100 \mathrm{~mm}$ showed a very good tolerance in both groups$3.66(6.33) \mathrm{mm}$ with carteolol with benzalkonium, $v 2.83$ (5.83) $\mathrm{mm}$ with preservative free carteolol ( $\mathrm{p}=0.27$, non-significant). No significant difference could be found between the two groups in grading of subjective symptoms, visual acuity, aesthesiometry, pupillary diameter, conjunctival oedema, epiphora, and fluorescein test scoring. None of these criteria changed significantly from baseline in any group.

Break up time, however, was significantly reduced compared with baseline by preserved carteolol at 3 hours $(10.4$ (5.9) seconds to 6.1 (3.9) seconds, $p=0.001)$, whereas benzalkonium free carteolol did not change the break up time significantly (baseline 9.1 (5.7) seconds; 3 hours 7.9 (5.5) seconds, not significant). At this time point, the decrease of break up time from baseline was significantly higher in the benzalkonium group $(-4.4$ (6.3) seconds) than in the preservative free one $(-1.1$ (6.4) seconds, $\mathrm{p}=0.04$ ).

IOP was similarly lowered in both groups, about $-3 \mathrm{~mm} \mathrm{Hg}$. This was approximately a $25 \%$ reduction, without any difference between the two treatments (Table 1). Blood pressure showed a very slight decrease after instillation of both formulations, less than 5 $\mathrm{mm} \mathrm{Hg}$ for diastolic pressure and less than 10 $\mathrm{mm} \mathrm{Hg}$ for systolic pressure, with no significant difference between the two groups. Resting pulse rate also decreased after instillation, with no significant difference between the two treatments (Table 2).

REPEATED INSTILLATIONS

After 3 days of treatment (six instillations), no difference could be found between the two 
Table 1 Results of pupillary diameter, fluorescein test, break up time, and IOP after instillation of one drop of carteolol with and without preservative (comparison by analysis of variance (SD))

\begin{tabular}{|c|c|c|}
\hline & $\begin{array}{l}\text { Carteolol without } \\
\text { benzalkonium }\end{array}$ & $\begin{array}{l}\text { Carteolol with } \\
\text { preservative }\end{array}$ \\
\hline \multicolumn{3}{|l|}{ Pupil diameter (mm) } \\
\hline Baseline & $3.1(0.8)$ & $3.3(0.7)$ \\
\hline $\mathrm{T} 0+30$ minutes & $3.1(0.7)$ & $3.3(0.7)$ \\
\hline $\mathrm{T} 0+1$ hour & $3.3(0.8)$ & $3.1(0.7)$ \\
\hline T0 +3 hours & $3.2(0.9)$ & $3.3(0.7)$ \\
\hline \multicolumn{3}{|c|}{ Fluorescein test (cotation $0-4$ ) } \\
\hline Baseline & 0 & 0 \\
\hline $\mathrm{T} 0+30$ minutes & $0.4(0.8)$ & $0.2(0.4)$ \\
\hline T0 + 1 hour & $0.4(0.8)$ & $0.3(0.5)$ \\
\hline T0 +3 hours & $0.4(0.7)$ & $0.3(0.7)$ \\
\hline \multicolumn{3}{|c|}{ Break up time (seconds) } \\
\hline Baseline & $9.0(5.1)$ & $10.4(5.9)$ \\
\hline $\mathrm{T} 0+30$ minutes & $8.1(5.4)$ & $7.9(5.7)$ \\
\hline $\mathrm{T} 0+1$ hour & $7.3(5.9)$ & $7.4(6.4)$ \\
\hline T0 +3 hours $\star$ & $7.9(5.5)$ & $6.1(3.9) \dagger$ \\
\hline \multicolumn{3}{|c|}{ Intraocular pressure $(\mathrm{mm} \mathrm{Hg})$} \\
\hline Baseline & $13.8(1.6)$ & $13.7(1.9)$ \\
\hline $\mathrm{T} 0+30$ minutes & $10.3(1.7)$ & $11.3(1.6)$ \\
\hline $\mathrm{T} 0+1$ hour & $10.5(1.9)$ & $10.1(1.4)$ \\
\hline T0 +3 hours & $10.5(1.9)$ & $10.8(1.9)$ \\
\hline
\end{tabular}

${ }^{\star}$ Decrease in BUT at 3 hours from baseline was significantly lower in the benzalkonium free group than in the preserved carteolol $(\mathrm{p}=0.04)$

†Significantly lowered compared with baseline $(\mathrm{p}=0.001)$

Table 2 Heart rate (SD) after a single instillation (pulses/minute). Statistical analysis did not show any difference between the two treatments

\begin{tabular}{lll}
\hline & $\begin{array}{l}\text { Carteolol without } \\
\text { benzalkonium }\end{array}$ & $\begin{array}{l}\text { Carteolol with } \\
\text { benzalkonium }\end{array}$ \\
\hline Baseline & $80.76(9.70)$ & $79.56(9.81)$ \\
T0 + 1 hour & $71.23(8.58)$ & $69.70(8.74)$ \\
T0 + 3 hours & $69.23(9.64)$ & $67.56(8.81)$ \\
\hline
\end{tabular}

treatments with regard to visual acuity, aesthesiometry, pupillary diameter, Schirmer's test, hyperaemia, oedema, epiphora, fluorescein test scores, or IOP (Table 3). Again a trend towards better preservation of break up time was found in the group without benzalkonium, as it decreased from 9.1 (5.7) to 8.4 (5.8) seconds (not significant) $v 10.4(5.9)$ to $7.7(5.5)$ seconds in the benzalkonium group $(p=0.04)$. A slight IOP decrease was found in both groups 8 hours after the last instillation (about $10 \%$ from the baseline and similar with both treatments). A very slight decrease in blood pressure was found in both groups (mean decrease of $5 \%$ from the baseline, less than 6 $\mathrm{mm} \mathrm{Hg}$ for systolic pressure, and $9 \%$, less than $5 \mathrm{~mm} \mathrm{Hg}$, for diastolic), whereas heart frequency did not change significantly from the baseline in any group.

Table 3 Distant visual acuity, pupil diameter, aesthesiometry, Schirmer's test, break up time, fluorescein test, and IOP after 3 days of treatment (SD)

\begin{tabular}{llll}
\hline & & $\begin{array}{c}\text { Carteolol without } \\
\text { benzalkonium }\end{array}$ & $\begin{array}{l}\text { Carteolol with } \\
\text { benzalkonium }\end{array}$ \\
\hline Distant visual acuity (/2O) & Baseline & $24.2(1.6)$ & $23.8(2.2)$ \\
Pupil diameter (mm) & 3 days & $24.8(2.0)$ & $24.2(2.2)$ \\
& Baseline & $3.1(0.8)$ & $3.38(0.75)$ \\
Aesthesiometry (mg/surface) & 3 days & $3.4(0.5)$ & $3.38(0.44)$ \\
Schirmer's test (mm at 5 minutes) & Baseline & $13.6(2.3)$ & $12.5(1.9)$ \\
Break up time (seconds) & 3 days & $11.4(0.6)$ & $11.4(0.9)$ \\
& Baseline & $25.7(11.7)$ & $20.60(12.68)$ \\
Fluorescein test (graded 0 to 4) & Baseline & $13.3(10.4)$ & $17.03(13.91)$ \\
IOP (mm Hg) & 3 days & $8.1(0.2)$ & $10.4(5.9)$ \\
& Baseline & 0 & $7.7(5.5)^{\star}$ \\
& 3 days & $0.1(0.3)$ & 0 \\
& Baseline & $13.8(1.7)$ & $0.1(0.4)$ \\
& 3 days & $12.4(1.8)$ & $13.7(1.9)$ \\
& (p) & $12.4(1.9)$
\end{tabular}

^Significantly decreased from baseline $(\mathrm{p}=0.04)$.

\section{Discussion}

Almost all antiglaucoma drugs are currently available in association with benzalkonium chloride, a quaternary cationic surfactant, used at concentrations ranging from $0.005 \%$ to $0.01 \%$. Its ocular toxicity was documented as early as 1941, and was found relevant at concentrations as low as $0.004 \% .^{9}$ Benzalkonium chloride through its surfactant effects alters tear fluid stability and reduces break up time. At a concentration of $0.005 \%$, benzalkonium chloride causes epithelial cell wrinkling and peeling with exposure of underlying cells. ${ }^{14}$ At $0.01 \%$, it may induce strong epithelial alterations, and at higher concentrations it causes strong damage to corneal stroma and endothelium.

Only a few studies have compared preservative free antiglaucoma drugs to preserved commercial preparations. In vitro, Williams et al ${ }^{15}$ investigated benzalkonium chloride, and three pure and preserved $\beta$ blockers (timolol, betaxolol, and levobunolol), in tissue cultures of human Tenon's capsule fibroblasts, and demonstrated irreversible toxicity of preservative and preserved drugs. Preservative free timolol showed significantly less toxicity than the commercial solution with $0.01 \%$ benzalkonium, and levobunolol was the least toxic, probably as a result of a lower concentration of benzalkonium chloride in this preparation $(0.004 \%$ benzalkonium). In experimental models, Young et $a l^{16}$ showed, after glaucoma surgery, more myofibroblasts in the conjunctiva of rabbits treated for 4 months before surgery with pilocarpine, timolol, or artificial tears with benzalkonium chloride. An increase of fibrous tissue has also been observed in rabbits treated with preparations of metipranolol and pilocarpine, preserved with benzalkonium and cetrimonium chloride respectively, for 3 months, compared with non-preserved drugs. ${ }^{17}$

In humans, a recent study of 20 patients by from timolol with benzalkonium to timolol without preservative could significantly increase tear turnover values, although break up time remained significantly lower both in benzalkonium and benzalkonium free timolol compared with normal control subjects, without a significant difference in the two groups. This may indicate that glaucoma drugs may impair the tear film, but that use of benzalkonium chloride entails additional side effects. In other studies in glaucoma patients, removal of benzalkonium chloride from a timolol preparation restored the permeability and the metabolism of corneal epithelium ${ }^{11}$ and improved break up time. ${ }^{10}$

However, these infrequent human studies were not prospective and randomised, nor did they compare in a homogeneous patient population preserved and preservative free preparations of antiglaucoma drugs. Our crossover randomised study was designed with healthy volunteers to look for differences of tolerance between two preparations of carteolol, with and without preservative, in short term use. We confirmed good tolerance for both preparations, which is consistent with the safety of this 
drug reported in clinical studies with preserved carteolol. ${ }^{13} 1819$

We also found in this study that the IOP lowering effect of carteolol was not reduced by suppressing benzalkonium. We observed that the decrease in IOP (around $2.5 \mathrm{~mm} \mathrm{Hg}$ at peak) was in accordance with previously published studies on carteolol. ${ }^{18-21}$ It has been suggested that benzalkonium chloride, through its toxic effects on ocular surface epithelia, enhances penetration of the active compound. Controversies thus remain concerning the effectiveness of unpreserved antiglaucoma drugs. Betaxolol without preservative appeared to be as efficient as the commercial solution in reducing $I O P, 22$ and De Jong et al ${ }^{11}$ confirmed that unpreserved timolol was both less toxic than, and as effective on IOP as, the preserved solution.

In the present work, we found a significantly decreased break up time after one drop of and after a 3 day treatment with preserved carteolol compared with the unpreserved preparation which did not modify tear fluid stability significantly. This is probably due to the surfactant property of benzalkonium chloride. However, these results in young healthy volunteers could be much more relevant in older glaucoma patients, who often suffer from various ocular surface disorders and quantitative or qualitative tear deficiency. Inflammatory changes can be found in the conjunctiva of a majority of multitreated glaucoma patients. Whether or not benzalkonium chloride is the main factor responsible for ocular surface toxicity remains to be determined. Only long term well controlled randomised prospective studies comparing preserved with unpreserved $\beta$ blockers, in patients with and without ocular surface diseases, can address this issue. Our study is one of the first attempts, but these results need to be confirmed in large assays in glaucoma patients for a conclusive investigation of the consequences of long term use of preservatives on fragile ocular structures. Studies of preservative effects may stimulate interest in developing unpreserved solutions for patients with a high risk of toxicity or undergoing filtering surgery.

Presented as a poster at the annual meeting of the American Academy of Ophthalmology, Chicago, 1996

This study was supported by Chauvin Company, Montpellier, France, but the authors have no financial interest in the drugs tested in this study or in the company.
1 Broadway DC, Grierson I, O'Brien C, Hitchings RA. Adverse effects of topical antiglaucoma medication. I The conjunctival cell profile. Arch Ophthalmol 1994;112:143745.

2 Sherwood MB, Grierson I, Millar L, Hitchings RA. Long-term morphologic effects of antiglaucoma drugs on the conjunctiva and Tenon's capsule in glaucomatous patients. Ophthalmology 1989;96:327-35.

3 Brandt JD, Wittpen JR, Katz LJ, Steinmann WN, Spaeth GL. Conjunctival impression cytology in patients with glaucoma using long-term topical medication. $A m \quad \mathcal{F}$ Ophthalmol 1991;112:297-301.

4 Baudouin C, Garcher C, Haouat N, Bron A, Gastaud P. Expression of inflammatory membrane markers by conjunctival cells in chronically treated glaucoma patients. Ophthalmology 1994;101:454-60.

5 Anders N, Wollensak J. Ocular pseudopemphigoid after topical drug administration. Klin Monatsbl Augenheilkd 1994;205:61-4.

6 Schwab IR, Linberg JV, Gioia VM, Benson WH, Chao GM. Foreshortening of the inferior conjunctival fornix associated with chronic glaucoma medications. Ophthalmology 1992;99:197-202.

7 Lavin MJ, Wormald RPL, Migdal CS, Hitchings RA. The influence of prior therapy on the success of trabeculectomy. Arch Ophthalmol 1990;108:1543-50.

8 Broadway DC, Grierson I, O'Brien C, Hitchings RA. Adverse effects of topical antiglaucoma medication. II. The outcome of filtration surgery. Arch Ophthalmol 1994;112: 1446-54.

9 Burstein NL. Preservative cytotoxic threshold for benzalkonium chloride and chlorhexidine digluconate in cat and
rabbit corneas. Invest Ophthalmol Vis Sci 1980;19:308-13.

10 Marquardt R, Schubert T. Modification of tear film break up time by beta-blocker eye drops without preservatives. Klin Monatsbl Augenheilkd 1991;199:75-8.

11 De Jong C, Stolwijk T, Kuppens E, De Keizer R, Van Best J. Topical timolol with and without benzalkonium chloride: epithelial permeability and autofluorescence of the cornea in glaucoma. Graefes Arch Clin Exp Ophthalmol 1994;232: $221-4$.

12 Kuppens EV, de Jong CA, Stiwijk TR, de Keizer RJ, van Best JA. Effect of timolol with and without preservative on the basal tear turnover in glaucoma. Br f Ophthalmol 1995; 79:339-42.

13 Chrisp P, Sorkin EM. Ocular carteolol. A review of its pharmacological properties, and therapeutic use in glaucoma macological properties, and therapeutic use in glaucon

14 Burstein NL. Preservative cytotoxic threshold for benzalkonium chloride and chlorhexidine digluconate in cat and rabbit corneas. Invest Ophthalmol Vis Sci 1980;19:308-13.

15 Williams DE, Nguyen KD, Shapourifar-Tehrani S, Steinmann WN, Spaeth GL. Effects of timolol, betaxolol and levobunolol on human Tenon's fibroblasts in tissue culture. Invest Ophthalmol Vis Sci 1992;33:2233-41.

16 Young TL, Higginbotham EJ, Zou X, Farber MD. Effects of topical glaucoma drugs on fistulized rabbit conjunctiva. Ophthalmology 1990;97:1423-7.

17 Mietz H, Niesen U, Krieglstein GG. The effect of preservatives and antiglaucomatous medication on the histopatholtives and antiglaucomatous medication on the histopathology of the conjun
$1994 ; 232: 561-5$.

18 Stewart WC. Carteolol, an ophthalmic $\beta$-adrenergic blocker with intrinsic sympathomimetic activity. F Glaucoma 1994; 3:339-45.

19 Zimmerman TJ. Topical ophthalmic beta-blockers: a comparative review. F Ocul Pharmacol 1993;9:373-84.

20 Berlin I, Marlel P, Uzzan B, Millon D, Hoang PL, Puech AJ. A single dose of three different ophthalmic beta-blockers antagonizes the chronotropic effect of isoproterenol in healthy volunteers. Clin Pharmacol Ther 1987;41:622-6.

21 Duff GR, Newcombe RG. The 12-hour control of intraocular pressure on carteolol $2 \%$ twice daily. Br 7 Ophthalmol lar pressure on

22 Denis $\mathrm{Ph}$, Demailly $\mathrm{Ph}$, Saraux H. Clinical evaluation of betaxolol in ophthalmic suspension with or without preservative agent in patients with glaucoma or ocular hypertension. F Fr Ophtalmol 1993;16:297-303. 